\title{
Study of Alum Sludge as a Soil Improver for Turmeric Growth
}

\author{
N. M. Zahari, N. H. Hassan, L. M. Sidek, C. K. Hua
}

\begin{abstract}
Alum sludge is the by-product resulted from the process in generation when aluminium sulphates are used to promote coagulation in the production of clean drinking water. Excessive of alum sludge is regarded as a waste product and disposed to the landfill can associated financial and environmental cost. This project primarily aimed for potential utilization of alum sludge as soil improver. Turmeric has been chosen as the sample plant to this project. The scope of the project involved the experiment of raw alum sludge and used alum sludge (alum that contain phosphate and nitrate) as a soil improvement by using simple lab scale and equipment to carry out the result of turmeric growth rate. The turmeric growth rate was determined by a few parameters by using different portion of raw alum sludge and used alum sludge. The effects on the plants by using different alum which are raw alum sludge and used alum sludge were successfully compared. Some portion of alum sludge can be used as soil improvements for beneficial use to turmeric instead of transporting off the island for landfill disposal has been determined.
\end{abstract}

Keywords - Aluminium sulphates, raw alum sludge, used alum sludge, soil improvement, turmeric growth rate

\section{Introduction}

When aluminium sulphates are used to promote coagulation in the production of clean drinking water, alum sludge is the by-product resulted from the process in the generation. To get rid of particles, colour and impurities particularly from the high turbidity raw waters, chemical coagulants are added to the raw waters during water treatment process. Aluminium sulphates or commonly called alum have been used by man since 4000 years ago [1]. Different chemicals can be used as coagulant such as iron salts and polyelectrolytes but the most frequently used as primary coagulating agents for water treatment processes by water industries across the world due to their effectiveness and low costs is alum [2].

N. M. Zahari*, N. H. Hassan, L. M. Sidek, C. K. Hua

College of Engineering

Civil Engineering Department/Universiti Tenaga Nasional

Putrajaya Campus

Malaysia
As the demand for drinking water is expanding, the alum sludge that generated by the processes is expanding along. Festival season may contribute to the expansion of alum sludge production from the water treatment process. Alum sludge is requiring further treatment before final disposal. Therefore, alum sludge is the most extensive by-product generated by the water industries globally. Economic and environmental criteria are particularly important determinants. Environmental protection considerations impose constraints on disposal and exclude disposal options that are likely to cause environmental damage. This study is aimed to determine the impact of alum sludge as a soil improvement towards turmeric plant for the potential utilization in agricultural sector. The study focuses on the turmeric growth rate by evaluate a few parameters by using different alum which are raw alum sludge and used alum sludge.

\section{A. Alum Sludge}

Suspended particles cannot be completely get rid of from water along apparent settling, even out when they are applying identical long detention times and overflow rates [3]. The most common coagulant is aluminium sulphate. It is generally referred to as alum. Occasionally certain synthetic organic chemicals, addressed polymers are added together along with the alum to act as coagulant aids [4]. The alum sludge is commonly mechanically dewatered and is currently treated as a waste which cannot be processed through conventional sewage sludge disposal methods and in many cases goes to landfill. The $\mathrm{pH}$ of alum sludge varied in the range of 5.12-8.0. It is within the typical range of 5.08.0 which is satisfactory for plant growth [5]. Composition of water treatment sludge is the principal elemental compositions of the dewatered sludge applied in this field of study are shown in Table 1.

Table I. Composition of oven-dried water treatment sludge

\begin{tabular}{lccc}
\hline Elements & Alum sludge & $\begin{array}{c}\text { Lime sludge } \\
\text { Magnesium }\end{array}$ & Lime-iron sludge \\
Silicon & 0.16 & 1.20 & 0.61 \\
Chlorine & 0.28 & 1.11 & 3.59 \\
Calcium & 0.12 & 0.17 & 0.12 \\
Manganese & 0.03 & 0.72 & 27.26 \\
Iron & 1.15 & 0.44 & 0.68 \\
Cobalt & 0.02 & 0.02 & 31.11 \\
Zinc & - & 0.60 & 0.18 \\
Sodium & 0.26 & 0.24 & 0.14 \\
Aluminum & 31.52 & 3.76 & - \\
Potassium & 0.41 & 0.07 & - \\
Titanium & 0.10 & 0.05 & - \\
Mercury & 0.31 & - & - \\
\hline
\end{tabular}

Source: Kim et al. (2013) [6] 


\section{B. Alum Sludge Disposal}

The selection of a specific disposal destination for alum sludge is one of the most important decisions to be made in water treatment system design, particularly for larger works. The choice rests between disposal to agriculture, landfill or incineration with landfill disposal of the ash residue [6,7]. It is influenced by the quantity of the alum sludge and the location of the works relative to potential disposal sites. The extent of processing prior to disposal to any of these sites is determined by technical, economic and environmental considerations [7].

\section{Tumeric}

Turmeric plant had been chosen as an indicator of the soil as a soil improver because it is of the plants that are normally fairly low maintenance and thus quite easy to grow. It is native to southern Asia, requiring temperatures between $20^{\circ} \mathrm{C}$ and $30^{\circ} \mathrm{C}$ which is also suitable to be plant indoor [9]. Therefore, it is easy to observe from one time to time. Turmeric normally reaching to a mature height of 3.25 feet which is $100 \mathrm{~cm}$ height thus, it is easy to be take care of and monitor. In addition, it is easily and does grow fine in pots or containers [8].

\section{Sandy Loam Soil}

Many soil types are suitable for planting. However, well drained sandy loam soils rich with organic matter are the most suitable soil type for turmeric. Turmeric grows well in sandy or clayey loam or red loamy soils having acidic to slightly alkaline $\mathrm{pH}$ value [9]. Sandy loam with a balance of organic matter is an ideal soil that holds water, air and nutrients is easier to work with earthworm nature and other soil dwelling insects oxygenate the soil and give organic matter with their decomposition.

\section{Methodology}

\section{A. Material and Equipment Preparation}

The materials that have been used for the experiment are one big pack of sandy loam soil, nine units of turmeric saplings and nine units of polybags. The size of the polybag is $20.32 \mathrm{~cm} \times 30.48 \mathrm{~cm}$. Then for the other main material which are raw alum sludge and used alum sludge (contain phosphate and nitrate) were collected at Uniten Laboratory as the material samples. For measuring the parameters of turmeric growth rate, scale tape and digital weight scale were required. Scoop planting set and gloves were needed to plant and dig out the turmeric plant. Water measuring cup is necessary for measure the water to pour to the turmeric plant.

\section{B. Alum Sludge and Sandy Loam Soil Portion and Turmeric Planting Preparation}

There are two sets of alum sludge to be tested on turmeric plants which are raw alum sludge and used alum sludge (contains phosphate and nitrate). There are four turmeric plants to be planted for one set of alum sludge in polybags. Every polybag contains different portion of alum sludge and sandy loam soil. The percentages of alum sludge content are $25 \%, 50 \%, 75 \%$ and $100 \%$ for both types of alum sludge in each polybag and the remaining percentage are for sandy loam soil content. Four different portions of raw alum sludge with sandy loam soil and another four different portions of used alum sludge which contains phosphate and nitrate with sandy loam soil were prepared for the turmeric planting.

\section{Experimental Setup}

The experiment was run in three months and the parameters that related to the project were measured every week except for the weight. The weight of the turmeric reading was taken at the first day before it will be planted and at the end of the project which is after three months for final reading. Nine polybags of turmeric contain different portion of alum sludge and sandy loam soil were prepared including the control sample as shown in Fig 1. All of the turmeric plants were tested to gain the growth rate by measuring the parameters which are the weight and the height of the turmeric plant, the width and length of turmeric leaves and number of leaves. Container or polybag is not necessary for turmeric planting because it will likely grow too large for a windowsill but as for this project, it is necessary to use polybag to differentiate the effect on turmeric plants by different portion of alum sludge and sandy loam soil used.

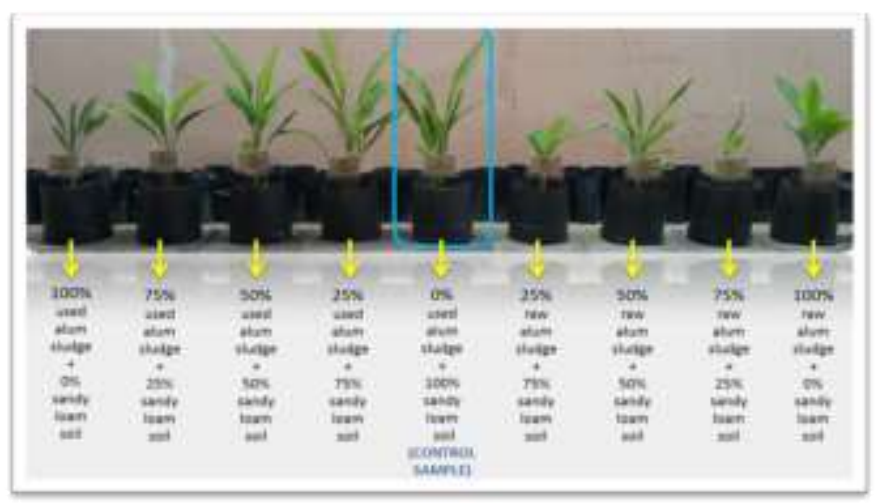

Figure 1. Turmeric plants after 3 months

\section{Result}

\section{A. Weight of Turmeric}

After three months, the highest reading for the weight of turmeric for raw alum sludge is $0.099 \mathrm{~g}$ which is for $100 \%$ and $50 \%$ of alum sludge content while the lowest reading is $0.038 \mathrm{~g}$ which is for $75 \%$ of alum sludge content. For used alum sludge, the highest reading for the weight of turmeric is $0.098 \mathrm{~g}$ which is for $50 \%$ of alum sludge content. However, the control sample weight is higher than the others which $0.105 \mathrm{~g}$. In term of rate, the most significant effect is on turmeric that contains $50 \%$ raw alum sludge and turmeric that contains 25\% used alum sludge as shown in Fig 2. 
Proc. of Sixth International Conference On Advances in Civil and Structural Engineering - CSE 2016.

Copyright $(\odot$ Institute of Research Engineers and Doctors. All rights reserved.

ISBN no. 978-1-63248-110-8 doi: 10.15224/ 978-1-63248-110-8-47

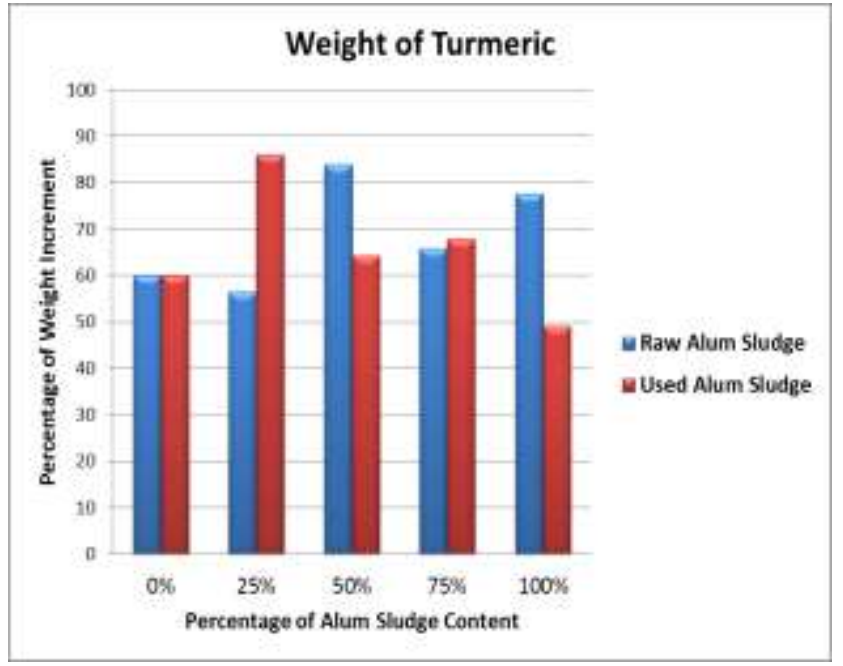

Figure 2. Growth rate in term of weight of turmeric

\section{B. Number of Leaves}

After three months, the highest number of leaves of the turmeric for raw alum sludge is 13 which is for $50 \%$ of alum sludge content while the lowest number is 6 which is for $75 \%$ of alum sludge content. For used alum sludge, the highest number of leaves of the turmeric is 10 which for $25 \%$ of alum sludge content while the lowest number is 7 which for $75 \%$ and $100 \%$ of alum sludge content. However, in term of rate, the most significant effect is on turmeric that contains no alum sludge at all which is the control sample as shown in Fig 3.

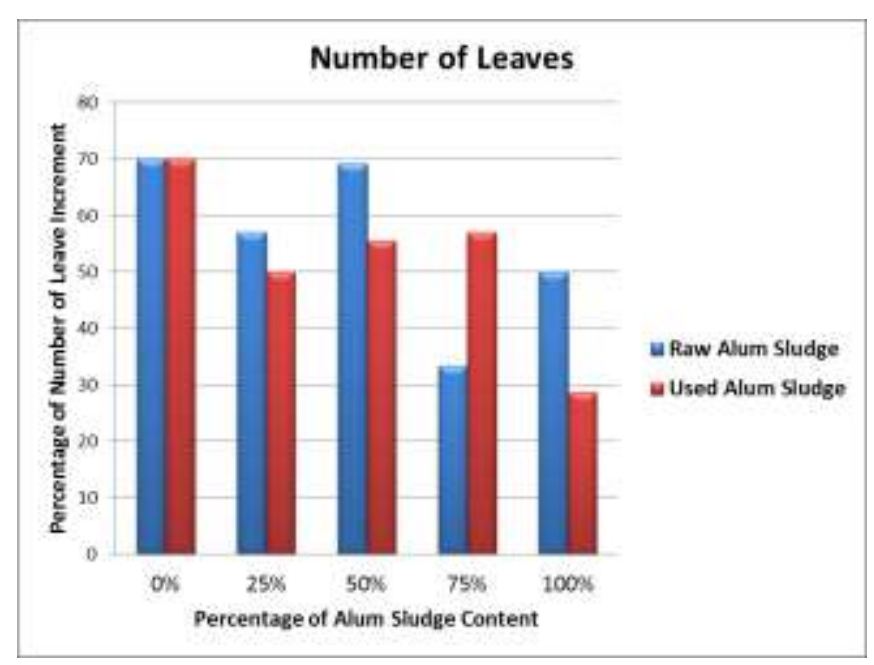

Figure 3. Growth rate in term of number of leaves

\section{Height of Turmeric}

After three months, the highest reading for the height of turmeric for raw alum sludge is $77.4 \mathrm{~cm}$ which is for $100 \%$ of alum sludge content while the lowest reading is $37.8 \mathrm{~cm}$ which is for $75 \%$ of alum sludge content. For used alum sludge, the highest reading for the height of turmeric is 71.4 $\mathrm{cm}$ which is for $25 \%$ of alum sludge content and the lowest reading is $47.5 \mathrm{~cm}$ for $100 \%$ alum sludge content. In term of rate, the most significant effect is on turmeric that contains
$50 \%$ raw alum sludge and turmeric that contains $25 \%$ used alum sludge as shown in Fig 4.

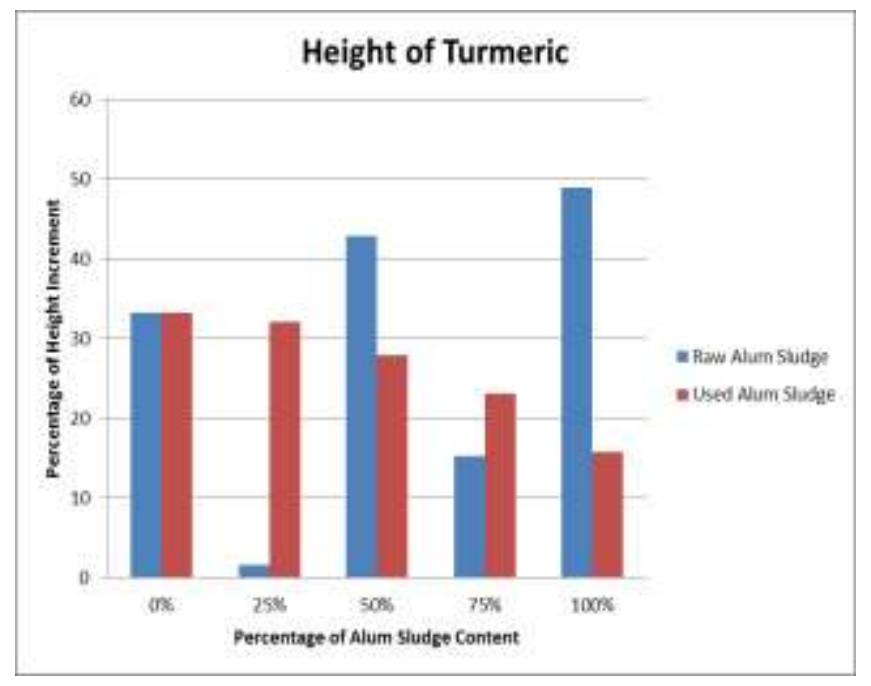

Figure 4. Growth rate in term of height of turmeric

\section{Discussion}

Alum sludge contains of nutrients. Plants need nutrient to survive and grow up. Technically, alum sludge can use as a medium of plants. All of the turmeric were growing up either slightly or significantly. The different growth rate of the result is regarding the portion of alum sludge content and the other factors. Different portion of alum sludge content affect the moisture of the soil. Caterpillars as a rule are voracious feeders and many of them are among the most serious of agricultural pests. In fact, many moth species are best known in their caterpillar stages because of the damage they cause to fruits and other agricultural produce [8]. The bites a bit of affect the size of leaf. Some of the turmeric was grown well.

Generally, the height of turmeric can reach $100 \mathrm{~cm}$ when reach maturity which is in 8 to 10 months [8]. For the three months long, the longest height of the turmeric had reached $77.4 \mathrm{~cm}$ which is turmeric in $100 \%$ raw alum sludge content that considered a significant growth rate. There are also other turmeric that grown well. The turmeric also grows with the additional of stalks and it could be more as the rhizomes become bigger and healthy. Somehow, the limited space of polybag also affected the growth rate. The rhizomes inside the soil were growing up as well. Therefore, insufficient space for the rhizomes to grow is one of the problems occurred.

\section{v. Conclusion}

Alum sludge contains of nutrients. Plants need nutrient to survive and grow up. Technically, alum sludge can use as a medium of plants. All of the turmeric were growing up either slightly or significantly. The different growth rate of the result is regarding the portion of alum sludge content and the other factors. Different portion of alum sludge content affect the moisture of the soil. Caterpillars as a rule are voracious feeders and many of them are among the most serious of agricultural pests. In fact, many moth species are best known in their caterpillar stages because of the damage they cause to fruits and other agricultural produce. Some of the turmeric was grown well. 
Generally, the height of turmeric can reach $100 \mathrm{~cm}$ when reach maturity which is in 8 to 10 months. For the three months long, the longest height of the turmeric had reached $77.4 \mathrm{~cm}$ which is turmeric in $100 \%$ raw alum sludge content that considered a significant growth rate. There are also other turmeric that grown well. The turmeric also grows with the additional of stalks and it could be more as the rhizomes become bigger and healthy. The limited space of polybag also affected the growth rate. The rhizomes inside the soil were growing up as well. Therefore, insufficient space for the rhizomes to grow is one of the problems occurred.

\section{Recommendation}

As for a better result, bigger polybags should be used for sufficient space for the rhizomes to grow. Soil properties should be experimented for getting absolute result and discussion. Other than that, for verify the exact physical properties of alum sludge and sandy loam soil, experiments such as specific gravity, moisture content and sieve analysis should be carried out.

\section{References}

[1] Donaldson, L. (1998). The Manufacture of Aluminium Sulphate. Chemical Processes in New Zealand, 2, 1F 1-3. Retrieved from http://www.nzic.org.nz/

[2] Dassanayake, K. B., Jayasinghe, G. Y., Surapaneni, A., \& Hetherington, C. (2015). A review on alum sludge reuse with special reference to agricultural applications and future challenges. Waste Management, 38(1), 321-335.

[3] Sharma, Y. (2014). Management and Control of Water. Hydro chemistry and water pollution studies for water management in Doon Valley, 156.

[4] Sahu, O. P., \& Chaudhari, P. K. (2013). Review on Chemical treatment of IndustrialasteWater Review on Chemical treatment. Journal of Applied Science Environmental Management, 17(2), 241257. http://dx.doi.org/10.4314/jasem.v17i2.8Liga, D. (2005). Growing Ginger, Galangal and Turmeric.

[5] Kim, G.J., Lee, S.S., Moon, H.S., Kang, I.M., (2002) Land application of alum sludge from water purification plant to acid mineral soil treated with acidic water. Soil Sci. Plant Nutr. 48 (1), 15-22.

[6] N.M.Zahari, C.K.Hua, L.M.Sidek (2015) Capability of Alum Sludge on Phosphate Concentration Reduction, Advances in Environmental Biology 9(1), 44-49

[7] N.M.Zahari, C.K.Hua, L.M.Sidek (2015). Behaviour of Waterworks Alum Sludge for Phosphate Removal, Advanced Materials Research Vol. 1113, 764-769

[8] Liga, D. (2005). Growing Ginger, Galangal and Turmeric

[9] Whiting, D., Wilson, C., \& Card, A. (2003). Estimating Soil Texture, 14(December 2003), 1-7.

[10] Thompson, J. R. (1987). Literature Review, Results Of An Illinois Survey And Effects Of Alum Sludge Application To Cropland. Wastes From Water Treatment Plants, 11.

About Author (s):

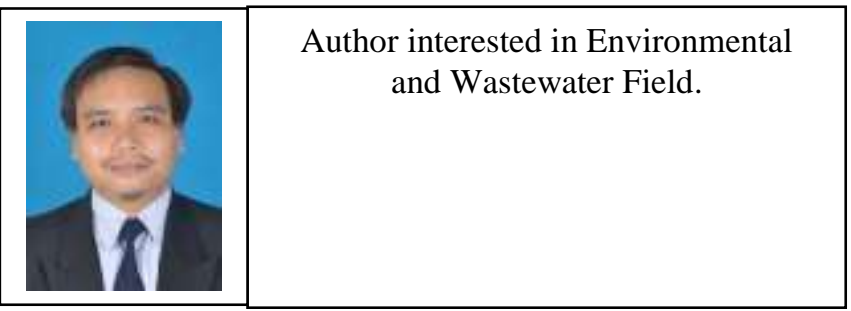

